\title{
Preparation and characterization of Zr-IV-containing Mg-Al-Cl layered double hydroxide
}

\author{
By H. Curtius ${ }^{1, *}$, K. Ufer ${ }^{2}$ and K. Dardenne ${ }^{3}$ \\ ${ }^{1}$ Institute for Energy Research (Safety Research and Reactor Technology, IEF-6), Research Centre Jülich, 52425 Jülich, Germany \\ 2 Institute of Mineralogy, TU Bergakademie Freiberg, Brennhausgasse 14, 09596 Freiberg, Germany \\ ${ }^{3}$ Forschungszentrum Karlsruhe GmbH, Institut für Nukleare Entsorgung (INE), P.O. Box 3640, 76021 Karlsruhe, Germany
}

(Received November 25, 2008; accepted in revised form February 26, 2009)

\section{Fuel elements / Secondary phases / \\ Layered double hydroxides / Zirconium / Stacking faults / EXAFS}

Summary. In order to contribute to the long-term safety analysis of direct disposed research reactor fuel elements, the corrosion behavior of these fuel-types in final repository relevant salt brines was determined. Due to the corrosion processes, radionuclides were mobilized first, but then trapped by the formed secondary phases.

A $\mathrm{Mg}$-Al layered double hydroxide (LDH) with chloride as interlayer anion was identified as one crystalline secondary phase component. The possibility to incorporate zirconium-IV into the lattice structure of the $\mathrm{Mg}-\mathrm{Al}-\mathrm{Cl} \mathrm{LDH}$ was investigated by a co-precipitation process. The element zirconium was chosen because it has a low absorption cross section for neutrons, and is therefore used for nuclear energy applications, such as for cladding fuel elements. No zirconium release was detected, when the obtained LDH was treated with an ammonium carbonate solution. The molar stoichiometry with respect to $\mathrm{Mg}, \mathrm{Al}$ and $\mathrm{Zr}$ remained stable and this is the first indication for the incorporation of zirconium.

For further examination, the material was analyzed by powder X-ray diffraction (XRD) combined with a Rietveld refinement. Due to a recursive calculation inside the Rietveld refinement, it was possible to derive structural parameters of the disordered LDH.

Further on, the Mg-Al-Zr-LDH was analyzed by EXAFS and the results did show that $\mathrm{Zr}$ is the central metal atom coordinated by $5 \mathrm{OH}$ groups and by one chloride.

\section{Introduction}

In Germany, the direct disposal of spent fuel elements is under investigation. At the IEF-6 the work is focused on research reactor fuel element. Two different fuel-types are under investigation. The dispersed metallic $\mathrm{UAl}_{x}$-type and the $\mathrm{U}_{3} \mathrm{Si}_{2}$-Al-type. At present three research reactors, the FRM-II-reactor (München), the FRG-I-reactor (Geesthacht) and the BER-II-reactor (Berlin) with a thermal output higher than $5 \mathrm{MW}$ are in operation in Germany. In these reactors dispersed $\mathrm{U}_{3} \mathrm{Si}_{2}$-Al-fuel is used. In general, three possible

\footnotetext{
*Author for correspondence (E-mail: h.curtius@fz-juelich.de).
}

back-end options for irradiated research reactor fuel elements exist in Germany [1]: first, irradiated research reactor fuel elements of USA origin can be sent back when these fuels were taken out of the reactor not later than May 2006. This affects basically the dispersed metallic $\mathrm{UAl}_{x}$-Al-fuel, which was used in the FRJ-II-reactor (Jülich) till May 2006. Secondly, reprocessing in Great Britain or France is possible and it is performed with respect to economical reasons. Thirdly, dry interim storage and later on, direct disposal in deep geological formations has been taken into account too. A possible repository under consideration is a salt mine, and the accident scenario for long-term safety analysis is a water ingress. Different leaching experiments with the dispersed metallic $\mathrm{UAl}_{x}$-Al-fuel (fuel used in the material test reactor FRJ-II) ${ }^{1}$ in highly-concentrated salt brines at $90{ }^{\circ} \mathrm{C}$ showed that the radionuclides were rapidly mobilized, but then trapped by the corrosion products [2]. Investigations [3] of these secondary corrosion products as a near field barrier against radionuclide migration indicated that one component is a $\mathrm{Mg}-\mathrm{Al}-\mathrm{Cl} \mathrm{LDH}$, also referred as a hydrotalcite-like compound (HTlc).

LDHs may be described by the general formula: $\left[\mathrm{M}(\mathrm{II})_{1-x} \mathrm{M}(\mathrm{III})_{x}(\mathrm{OH})_{2}\right]^{x+}\left(\mathrm{A}^{n-}\right)_{x / n} \cdot m \mathrm{H}_{2} \mathrm{O}$, where $\mathrm{M}(\mathrm{II})$ and $\mathrm{M}(\mathrm{III})$ are di- and trivalent metals respectively, and $\mathrm{A}^{n-}$ is an anion. Their structure is based on brucite-like layers, in which a divalent cation is located in the center of oxygen octahedra and two-dimensional infinite layers are formed by edgesharing of the octahedra. Partial isomorphous substitution of divalent cations for trivalent ones results in a positive charge on the layers. This charge is compensated by the presence of anions in the interlayer [4]. In the free space of this interlayer, water molecules are also present. The main features of LDH structures and of LDH properties are determined by the nature of the brucite-like sheet, by the type of stacking of the brucite-like sheets, by the amount of water and by the position and type of anions in the interlayer. It should be pointed out that a change in the brucite-like layer will result in differ-

\footnotetext{
${ }^{1}$ The MTR-FE of the DIDO type contains $20 \mathrm{wt} \% \mathrm{U}-\mathrm{Al}$ alloy with an initial enrichment of $80 \%$ in ${ }^{235} \mathrm{U}$. The fuel alloy plates with a thickness of $0.6 \mathrm{~mm}$ (meat) are covered on both sides with aluminium claddings of $0.38 \mathrm{~mm}$, the total thickness is then $1.36 \mathrm{~mm}$. The spent fuel element will be disposed in a cast iron POLLUX container.
} 
ent properties of the LDH. A change in the brucite-like sheet is possible by changing the stoichiometry of the metal ions present or by an exchange of the metal ions.

In order to achieve to the safety of long-term disposed fuel elements in an underground disposal site, the migration of radiotoxic elements through the geosphere must be evaluated. The existing multibarrier-system should prevent that, due to corrosion processes of the fuel containment and of the fuel itself, the mobilized radionuclides will be released to the biosphere. The corrosion products (secondary phases) formed can be regarded as first barrier with respect to radionuclide mobilization. As controlling retardation processes the surface complexation, the ion exchange and the co precipitation can be mentioned. Ionic exchange or surface complexation reactions are reversible processes. On the contrary the co precipitation process leads to an incorporation of the element in the lattice structure and is an irreversible process. A remobilization of the element is only possible when a change in the chemical condition is that significant that the host component itself will dissolve.

We already demonstrated that an isomorphous substitution of the trivalent aluminum, present in the $\mathrm{Mg}-\mathrm{Al}-\mathrm{Cl}$ LDH, by the trivalent europium [5], and by the trivalent samarium [6], is possible. Within this substitution the net positive charge in the brucite layer remains constant, hence the value of the AEC (anion exchange capacity) remains constant too. An increase of the AEC value can be achieved by increasing the number of trivalent ions in the layer within permissible limits. Alternatively, partial substitution of the $\mathrm{Mg}$-II or Al-III ion by a tetravalent metal ion, may increase the net positive charge in the brucite layer and hence the $\mathrm{AEC}$ value, too. An increase in the AEC value is desirable because then the LDH can remove higher amounts of anionic radionuclide species. In future work the retention of repository-relevant radionuclide anionic species like selenite, iodine and pertechnetate in repository-relevant aquatic phases is aspired. The influence of the increased AEC-value in view of the retardation of anionic species was already studied by Das et al. [7]. They investigated the adsorption of hexavalent chromium and selenite on uncalcinated and calcinated Mg-Al-LDHs containing zirconium-IV in the main layer. The first synthesis of a Mg-Al-LDH containing $\mathrm{Zr}$ in the brucite layer but with carbonate as interlayer anion was reported by Velu et al. [8]. Nevertheless, these results were discussed by Intissar et al. [9] in detail. By use of X-ray absorption and Mössbauer spectroscopy they showed, that the tetravalent cation is segregated from the LDH structure and forms amorphous M-IV oxide-like particles.

In the present paper we report the preparation and detailed characterization of a layered material possessing the hydrotalcite-like structure containing magnesium, aluminum and the tetravalent element zirconium in the hydroxide layer with chloride as interlayer anion. From XRD and EXAFS measurements the presence of Zr IV oxide particles can be ruled out.

\section{Experimental}

Deionised water was boiled and stored under an argon atmosphere before use. The chemicals were of analytical grade and used without further treatment. All experiments were performed under an argon atmosphere.

\subsection{Synthesis of the Mg-Al-Zr-Cl LDH}

The Mg-Al-Zr-Cl LDH was obtained according to the following co precipitation process: $250 \mathrm{~mL}$ of water were placed in a three-necked glass flask and a $\mathrm{pH}$ of 10 was adjusted using $2 \mathrm{M} \mathrm{NaOH}$. A mixed aqueous solution of $\mathrm{MgCl}_{2} \cdot 6 \mathrm{H}_{2} \mathrm{O}(0.3 \mathrm{M})$ and $\mathrm{AlCl}_{3} \cdot 6 \mathrm{H}_{2} \mathrm{O}(0.09 \mathrm{M})$ and $\mathrm{ZrOCl}_{2} \cdot 8 \mathrm{H}_{2} \mathrm{O}(0.01 \mathrm{M})$ in $250 \mathrm{~mL}$ water was added over a period of $5 \mathrm{~h}$ while the $\mathrm{pH}$ was maintained at 10 by addition of $2 \mathrm{M} \mathrm{NaOH}$. The temperature was maintained at $70{ }^{\circ} \mathrm{C}$. After the addition was complete, the temperature was raised to $90^{\circ} \mathrm{C}$ and stirring was continued for $24 \mathrm{~h}$. After cooling to room temperature, the formed precipitate was filtered and then dialyzed at $60^{\circ} \mathrm{C}$. For that purpose a dialysis hose was filled with the substance and placed in $2 \mathrm{~L}$ vessel containing deionised water. The water was changed until it was chloride-free (chloride measurements were performed with the cuvette test LCK 311, DR. LANGE). The precipitate was filtered and dried in a desiccator.

\subsection{Chemical analysis}

The obtained substance was characterized by photometry, DTA-TGA, FTIR, ICP-OES, SEM-EDX, EXAFS and XRD. For DTA-TGA, SEM-EDX, XRD, EXAFS and FTIR measurements, dry samples were milled to powder. For photometric and ICP-OES measurements the solid samples were dissolved in $2 \mathrm{M} \mathrm{HNO}_{3}$. Furthermore $1 \mathrm{~g}$ of the synthesized $\mathrm{Mg}-\mathrm{Al}-\mathrm{Zr}-\mathrm{Cl} \mathrm{LDH}$ was treated with $50 \mathrm{~mL}$ of an ammonium carbonate solution $(1 \mathrm{~mol} / \mathrm{L})$ at room temperature for $24 \mathrm{~h}$. This procedure was performed to distinguish between sorbed and incorporated $\mathrm{Zr}$ species. A change in the metal ion stochiometry is expected, when $\mathrm{Zr}$ is only sorbed and not incorporated. Then the solid was separated by filtration, washed with $10 \mathrm{~mL}$ water and dried at $70^{\circ} \mathrm{C}$.

$500 \mu \mathrm{L}$ of the filtrate was added to $49.5 \mathrm{~mL}$ of a $0.1 \mathrm{M}$ nitric acid solution and this solution was analyzed by ICPOES in order to determine the amounts of $\mathrm{Mg}, \mathrm{Al}$ and $\mathrm{Zr}$. To determine the $\mathrm{Mg}, \mathrm{Al}$ and $\mathrm{Zr}$ molar ratios of the solid, an ICP-OES analysis was performed as follows:

$100 \mathrm{mg}$ of the solid was dissolved in $10 \mathrm{~mL} 2 \mathrm{M}$ nitric acid. This solution was diluted $(1: 1000)$ with a $0.1 \mathrm{M}$ nitric acid solution and the measurement was performed.

To obtain detailed information about the incorporation of $\mathrm{Zr}$, investigations with XRD and EXAFS were performed.

\subsection{X-ray diffraction (XRD)}

Prior to the X-ray diffraction measurements, an internal standard (10.0 wt.-\% zincite) was added and the sample was hand-ground in an agate mortar. For the specimen preparation the top loading technique was used. The sample was measured on a 3003TT (General Electric) diffractometer (Bragg-Brentano geometry, $\mathrm{Cu} K_{\alpha}$ radiation generated at $40 \mathrm{kV}$ and $40 \mathrm{~mA}$ ) equipped with an automatic divergence slit irradiating $10 \mathrm{~mm}$ sample length, a $0.5 \mathrm{~mm}$ detector slit, a secondary beam graphite monochromator, a point detector and a sample spinner. The sample was measured from $5^{\circ}$ to 
$85^{\circ} 2 \Theta$ with a step size of $0.03^{\circ} 2 \Theta$ and a measuring time of $20 \mathrm{~s}$ per step.

\subsection{Rietveld refinement}

The principle of the Rietveld method [10] consists of the computation of synthetic diffraction patterns from a given structural model. This data will be fitted to experimental data by a non-linear least squares minimization. The quality of the refinement can be judged by the agreement index $R_{\text {wp }}$, which contains the differences of measured and observed data and its comparison to $R_{\text {exp }}$, the theoretical minimum value for $R_{\mathrm{wp}}$ [11].

The Rietveld analysis allows an insight in structural details of crystalline materials and therefore it is suitable for the characterization of the LDH.

For the refinement, the program BGMN was used [12]. BGMN contains a structure description language and offers the possibility of a complex manipulation of the structure factors and a solver for linear equation systems. Therefore a recursive treatment of diffraction effects from faulted layer stackings, similar to DIFFaX simulations [13] can be performed within a Rietveld refinement [6].

From previous investigations [5] it is known that LDHs develop a disordered stacking of the two polytypes $2 \mathrm{H}_{1}$ and $3 R_{1}$. Both polytypes form trigonal prismatic interlayer polyhedra. In the $3 \mathrm{R}_{1}$ structure adjacent layers are translated by a stacking vector $(2 / 3,1 / 3,1 / 3)$ relative to each other. The $2 \mathrm{H}_{1}$ polytype is formed by an alternate stacking of layers which are rotated around $180^{\circ}$ parallel to the adjacent layers. In this work the probability of these two stackings could be refined. The layer structure is derived from a description of a Cl-LDH $\left(3 \mathrm{R}_{1}\right)$ by Ennadi et al. [14] Due to the disordered stacking, the symmetry is reduced from the original point group $R-32 / m$ (3 layers per unit cell) to $P 3 m 1$ (one layer per unit cell). In addition to the atomic positions of the interlayer atoms $(\mathrm{Cl}$ and oxygen to represent water) as proposed by Ennadi et al. [14], several further positions were tested. The initial occupancies of atomic positions are derived from chemical analysis. The occupancies of the cations were not refined. For $\mathrm{ZnO}$ only lattice parameters, peak broadening parameters and a scaling factor was refined. As non-structural parameters, the zero point, the sample displacement error and a Lagrange polynomial of 5th degree for background modeling were refined. BGMN includes a fundamental parameter approach to model the peak profiles [15]. The instrument-dependent part of the diffraction profile is predetermined by a ray tracing procedure.

\subsection{Extended X-ray absorption fine structure (EXAFS)}

$\mathrm{Zr} K \mathrm{X}$-ray absorption fine structure (XAFS) spectra are recorded at the INE-beamline (ANKA, Karlsruhe, Germany). Spectra are energy calibrated to the first inflection point in the XANES of a $\mathrm{Zr}$ foil $(17.998 \mathrm{keV})$ measured simultaneously. The $\mathrm{Zr}$-doped LDH XAFS is recorded at room temperature in transmission-mode using Ar-filled ionization chambers at ambient pressure. Ge $\langle 422\rangle$ crystals are used in
Table 1. Metric parameters of the $\mathrm{LDH}$ with $\mathrm{Mg} / \mathrm{Al}$ as center ( $R=$ distance between the central atom chosen, here $\mathrm{Mg} / \mathrm{Al}$ (both share the same crystallolgraphic site) and the backscattering atom, $N=$ coordination numbers) [18].

\begin{tabular}{lcc}
\hline Backscatterer & $N$ & $R(\AA) \mathrm{LDH}$ \\
\hline $\mathrm{O}$ (from OH) & 6 & 2.03 \\
$\mathrm{Al} / \mathrm{Mg}$ & 6 & 3.06 \\
$\mathrm{O}$ (from OH) & 6 & 3.67 \\
$\mathrm{C}$ & 2 & 4.00 \\
$\mathrm{O}$ & 6 & 4.19 \\
\hline
\end{tabular}

the monochromator, operating in fixed-exit mode. The incident intensity is held constant by means of a piezo-driven feedback system. The parallel alignment of the crystal faces is detuned to $\sim 70 \%$ of the maximum beam intensity. The XAFS sample is pressed in dried form into a polyethylene pellet of $13 \mathrm{~mm}$ diameter.

EXAFS fits are performed with Artemis [16] part of the Ifeffit package [17], using phase and amplitude data calculated for a 9 atom cluster derived from the undoped LDH structure [18] (Table 1). The cell parameters are increased to account for the larger size of the $\mathrm{Zr}$ cation. Single path scattering files for phase and amplitude are used for the second coordination sphere. The k-range used for the fit is $\left(2.33-13.93 \AA^{-1}\right)$ and fits are performed in the $R$-space on the $k^{2}$-weighted data.

\section{Results and discussions}

\subsection{Characteristics of LDHs}

The $\mathrm{Mg}-\mathrm{Al}-\mathrm{Zr}-\mathrm{Cl} \mathrm{LDH}$ was prepared according to a described co-precipitation method [19]. Little modifications were performed with regard to the purification and drying steps. For the synthesized double layered hydroxide a $\mathrm{Mg} / \mathrm{Al} / \mathrm{Zr}$ mole ratio of $3: 0.93: 0.099$ was determined by ICP-OES. Chloride was determined photometrically using a cuvette test LCK 311 (DR. LANGE). Due to the molar stoichiometry of the metal ions present in the main layer, the number of hydroxylgroups in the main layer must be eight

In the DTA-TGA thermogram the first endothermic peak occurs between room temperature and $275^{\circ} \mathrm{C}$, with its maximum at $142.5^{\circ} \mathrm{C}$, corresponding to a weight loss of $14.7 \%$, and is due to desorption of the interlayer water. The second endothermic peak between $275^{\circ} \mathrm{C}$ and $600{ }^{\circ} \mathrm{C}$ indicates partial dehydroxylation in the main layer and elimination of chloride in the interlayer. This assumption was drawn due to the results from Roelofs et al. [20], who investigated the thermal decomposition of Mg-Al-LDHs in detail. They showed that the dehydroxylation in the main layer depend on the basic properties of the interlayer anion.

The IR-spectra show strong hydroxyl and water stretching and bending bands at 3482 and $1636 \mathrm{~cm}^{-1}$. Metal-Ovibration bands appear in the region 1000 to $550 \mathrm{~cm}^{-1}$. $A$ very weak adsorption band due to adsorbed $\mathrm{CO}_{3}{ }^{2-}$ was present at $1376 \mathrm{~cm}^{-1}$. The presence of the divalent carbonate ion can be explained by the preparation of the $\mathrm{KBr}$ phase, which was not performed under an inert gas atmosphere, and by the high affinity of this ion towards LDHs. 


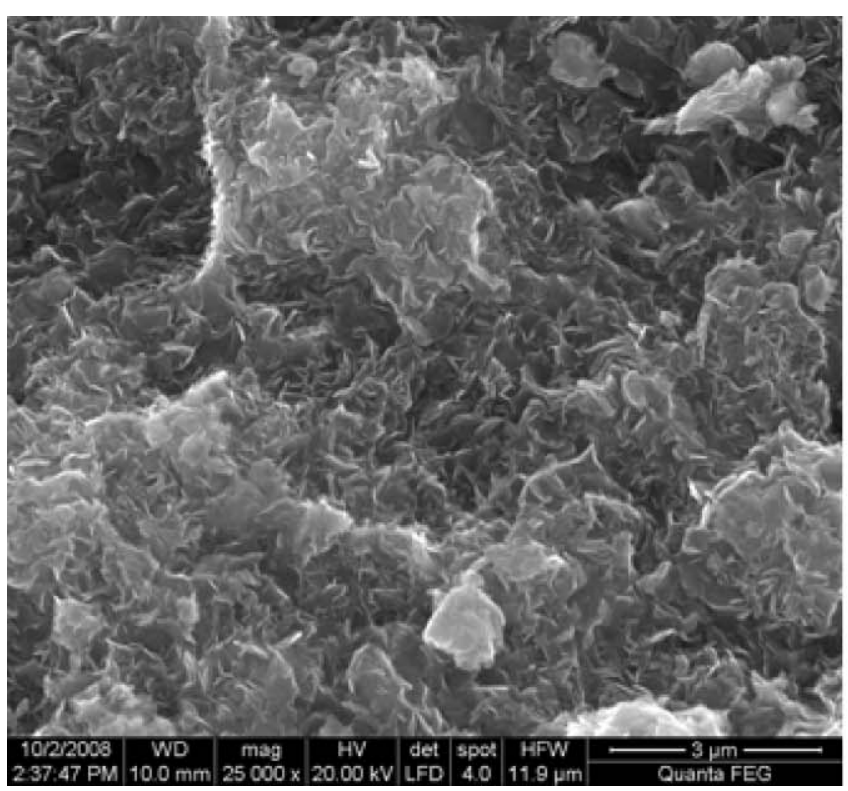

Fig. 1. Morphology of the Mg-Al-Zr-LDH, investigated by SEM.

From these results the formula of the $\mathrm{Mg}-\mathrm{Al}-\mathrm{Zr}-\mathrm{Cl} \mathrm{LDH}$ can be derived as $\left[\mathrm{Mg}_{3} \mathrm{Al}_{0.93} \mathrm{Zr}_{0.099}(\mathrm{OH})_{8}\right] \mathrm{Cl}_{0.94}\left(\mathrm{CO}_{3}{ }^{2-}\right)_{0.03}$. $2.71 \mathrm{H}_{2} \mathrm{O}$.

Eight hydroxyl-groups must be present in the main layer because the LDH structure is based on brucite-like layers, in which the divalent cation is located in the center of oxygen octahedra and two-dimensional infinite layers are formed by edge-sharing of the octahedral.

The morphology of the Mg-Al-Zr LDH obtained was investigated by SEM. The sand rose crystal structure (Fig. 1), typical for LDHs [21], can be clearly seen.

Then the element distribution was determined by EDX and theses results did show a homogeneous distribution and no other phase was observed.

For the solid a specific surface area of $48 \mathrm{~m}^{2} / \mathrm{g}$ was determined by BET and a cationic exchange capacity of $66 \mathrm{mmol} / 100 \mathrm{~g}$ was obtained by a complexation reaction with $\mathrm{Cu}$-II-triethylentetraamin.

Furthermore, the treatment of the $\mathrm{Mg}-\mathrm{Al}-\mathrm{Zr}-\mathrm{Cl} \mathrm{LDH}$ with an ammoniumcarbonate solution [22] did not result in any change of the $\mathrm{Mg}-\mathrm{Al}-\mathrm{Zr}$ molar ratios, indicating that the $\mathrm{Zr}$ is incorporated. For $\mathrm{Zr}$ species, which are sorbed at the LDH surface, we expect an interaction with the strong complexation agent, leading to the formation of carbonate complexes. These components were neither detected in solution nor in the solid.

\subsection{XRD measurements}

Table 2 shows the structural results of the Rietveld refinement of the $\mathrm{Mg}-\mathrm{Al}-\mathrm{Zr}-\mathrm{Cl} \mathrm{LDH}$. It was found that the original position for the interlayer chloride, as proposed by Ennadi et al. [14] did not lead to a satisfying result. Attempts to refine the position in the $a 1-a 2$ plane showed that the chloride has a tendency to move on a position perpendicular to the hydrogen, which corresponds to the Wyckoff position $b$ (space group $P 3 m 1$ ). In the final refinement only the interlayer water was positioned on the site proposed by

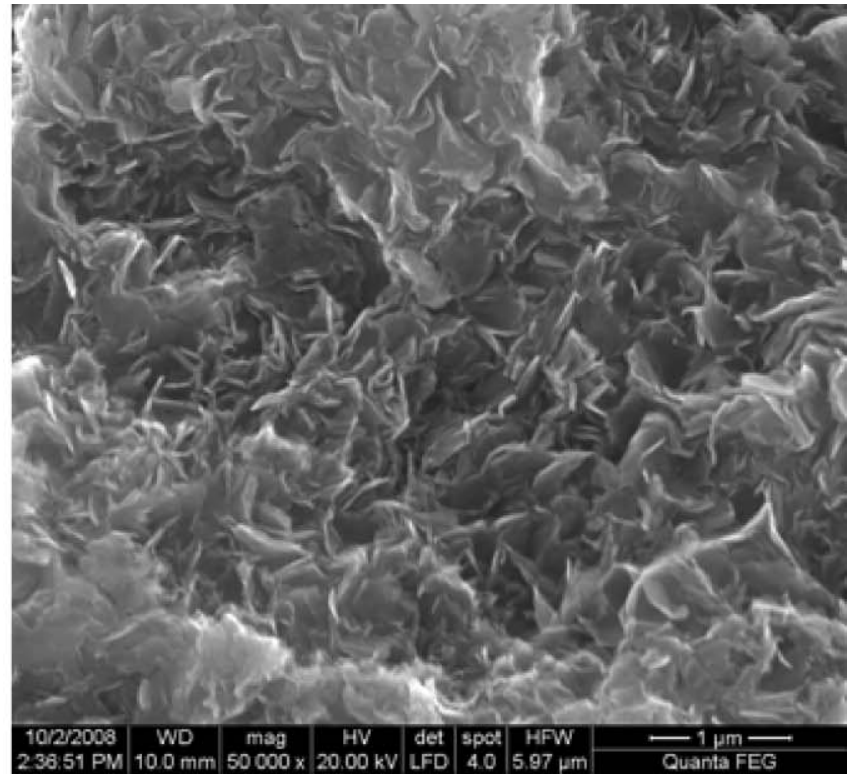

Table 2. Refinement results of $\mathrm{Mg}-\mathrm{Al}-\mathrm{Zr}-\mathrm{Cl} \mathrm{LDH}\left(R_{\mathrm{wp}}\right.$ and $R_{\exp }=$ agreement indices, $a$ and $c=$ lattice constants, $p(3 R 1)=$ probability for $3 R 1$ stacking, $p(\mathrm{Cl})$ and $p\left(\mathrm{H}_{2} \mathrm{O}\right)=$ occupancy of $\mathrm{Cl}$ resp. $\mathrm{H}_{2} \mathrm{O}$, $\mathrm{ESD}=$ estimated standard deviation).

\begin{tabular}{lccl}
\hline & Start parameters & Refinement & ESD \\
\hline$R_{\text {wp }}(\%)$ & & 9.14 & \\
$R_{\text {exp }}(\%)$ & & 3.38 & \\
$a(\AA)$ & 3.06 & 3.0718 & 0.0011 \\
$c(\AA)$ & 8.00 & 8.0002 & 0.0045 \\
$p(3 R 1)$ & 0.5 & 0.5129 & 0.0044 \\
$p(\mathrm{Cl})$ & 0.235 & 0.0264 & 0.0051 \\
$p\left(\mathrm{H}_{2} \mathrm{O}\right)$ & 0.25 & 0.0777 & 0.0012 \\
$\mathrm{LDH}($ wt. $\%)$ & & 89.04 & 0.14 \\
$\mathrm{ZnO}($ wt. $\%)$ & & 10.96 & 0.14 \\
\hline
\end{tabular}

Ennadi et al. [14] and chloride was fixed on Wyckoff position $b$. However, the occupancy of the chloride strongly decreased. This indicates that this position is also not suitable for a satisfying description of the atomic arrangement. This is illustrated in the strong misfit of the intensity of the 110 reflection (angular position at 60.06) (Fig. 2).

Unfortunately, so far there exists no suitable model in literature to describe the position of the chloride. Apart from this drawback, the refinement produced some significant structural parameters. The probability for the $3 R_{1}$ stacking is close to 0.5 , this shows that this LDH is highly disordered. The $a$ and $c$ lattice constant show typical values for a $\mathrm{Cl}$ $\mathrm{LDH}$. Both values, the stacking probability and the lattice constants, have no influence on the intensity of the 110 reflection [5].

The initial content of the $\mathrm{ZnO}$ admixture was refined as 10.96 wt. \%. This overestimation could be explained by an additional amorphous component (9.7 wt. \%, ESD = 1.3 wt. \%). However, the uncertainties in the determination of the amorphous content are relatively high and, consequently, a quantification of a small amount with large error seems to be critical. 
Table 3. Metric parameters $\left(R=\right.$ distances, $N=$ coordination numbers, $\sigma^{2}=$ EXAFS Debye-Waller factors, $\Delta E_{0}=$ relative energy shifts) from least squares analysis of FT data. $S_{0}^{2}$ is held constant at 1.0 .

\begin{tabular}{lcccccc}
\hline Sample & Backscatterer & $\begin{array}{c}R(\AA) \\
( \pm 0.01)\end{array}$ & $\begin{array}{c}N \\
( \pm 20 \%)\end{array}$ & $\sigma^{2}\left(\AA^{2}\right) \times 10^{-3}$ & $\begin{array}{c}\Delta E_{0} \\
(\mathrm{eV})\end{array}$ & $\begin{array}{c}\text { goodness } \\
\text { of fit }(\%)\end{array}$ \\
\hline Zr-doped LDH & $\mathrm{O}$ & 2.13 & 5.0 & 7.0 & -9.7 & 1.0 \\
Zr-doped LDH & $\mathrm{Cl}$ & 2.45 & 0.9 & 9.8 & -5.6 & 1.0 \\
Zr-doped LDH & $\mathrm{Al} / \mathrm{Mg}$ & 3.51 & 2.3 & 6.3 & -0.9 & 1.0 \\
\hline
\end{tabular}

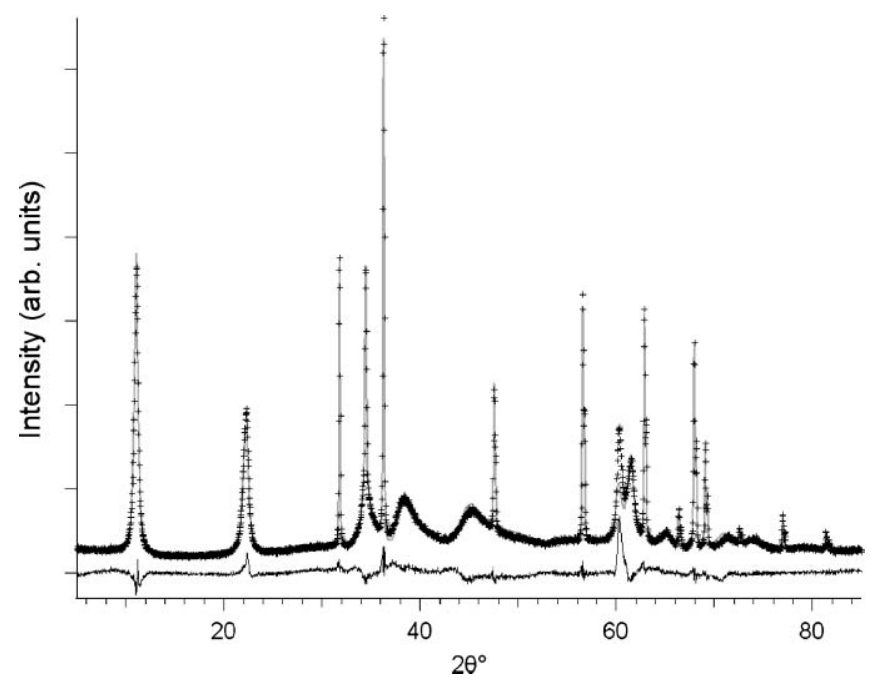

Fig. 2. Rietveld refinement of the $\mathrm{Mg}-\mathrm{Al}-\mathrm{Zr}-\mathrm{Cl} \mathrm{LDH}$. Gray line: calculated intensity; +: observed intensity, black line: difference curve.

\subsection{EXAFS measurements}

The data are well reproduced using 3 shells within the FT range (1.1-3.4 $\AA$ ) as shown Fig. 3. The fit results are given in Table 3. The first coordination sphere contains $5 \mathrm{O}$ atoms at $2.13 \AA$ with a Debye-Waller factor $\left(\sigma^{2}\right)$ of $7.0 \times 10^{-3} \AA^{2}$ and $1 \mathrm{Cl}$ atom at $2.45 \AA$ with a $\sigma^{2}$ of $9.8 \times 10^{-3} \AA^{2}$. The Debye-Waller factor is a parameter accounting for the molecular structural and thermal disorder of a sample, static and thermal disorder from the point of view of the absorber atom (here $\mathrm{Zr}$ ). It traduces the distance distribution of the coordination shell considered.

The presence of a $\mathrm{Cl}$ atom was not expected in the first coordination shell but no satisfactory fit can be achieved without adding the chlorine atom.

The structural incorporation of the $\mathrm{Zr}$ dopant is comparable to $\mathrm{Eu}$ in $\mathrm{LDH}$ [5]. The $\mathrm{Zr}$ is six-fold coordinated but a chlorine atom has replaced an oxygen atom in the first coordination shell.

As for Eu-doped LDHs, the $\mathrm{Al}$ shell is more distant as expected for isotropic extension of the unit cell. Circa $2 \mathrm{Al}$ atoms are found at $3.51 \AA(1.7 \mathrm{Al}$ at $3.45 \AA$ for $\mathrm{Eu})$. The reduced $\mathrm{Al}$ coordination number compared to the expected value of 6 (see Table 1) as well as the missing associated $\mathrm{O}$ shell (from $\mathrm{OH}$ ), indicates either disorder in the $\mathrm{Zr}$ near neighbour structure, with larger radius, or that $\mathrm{Zr}$ does not replace $\mathrm{Al} / \mathrm{Mg}$ exactly at their lattice position. No $\mathrm{Zr}-\mathrm{Zr}$ interaction can be evidenced, excluding the formation of cluster or polynuclear species such in $\mathrm{Zr}$ oxide or hydroxide within the EXAFS detection limit. It is likely that the
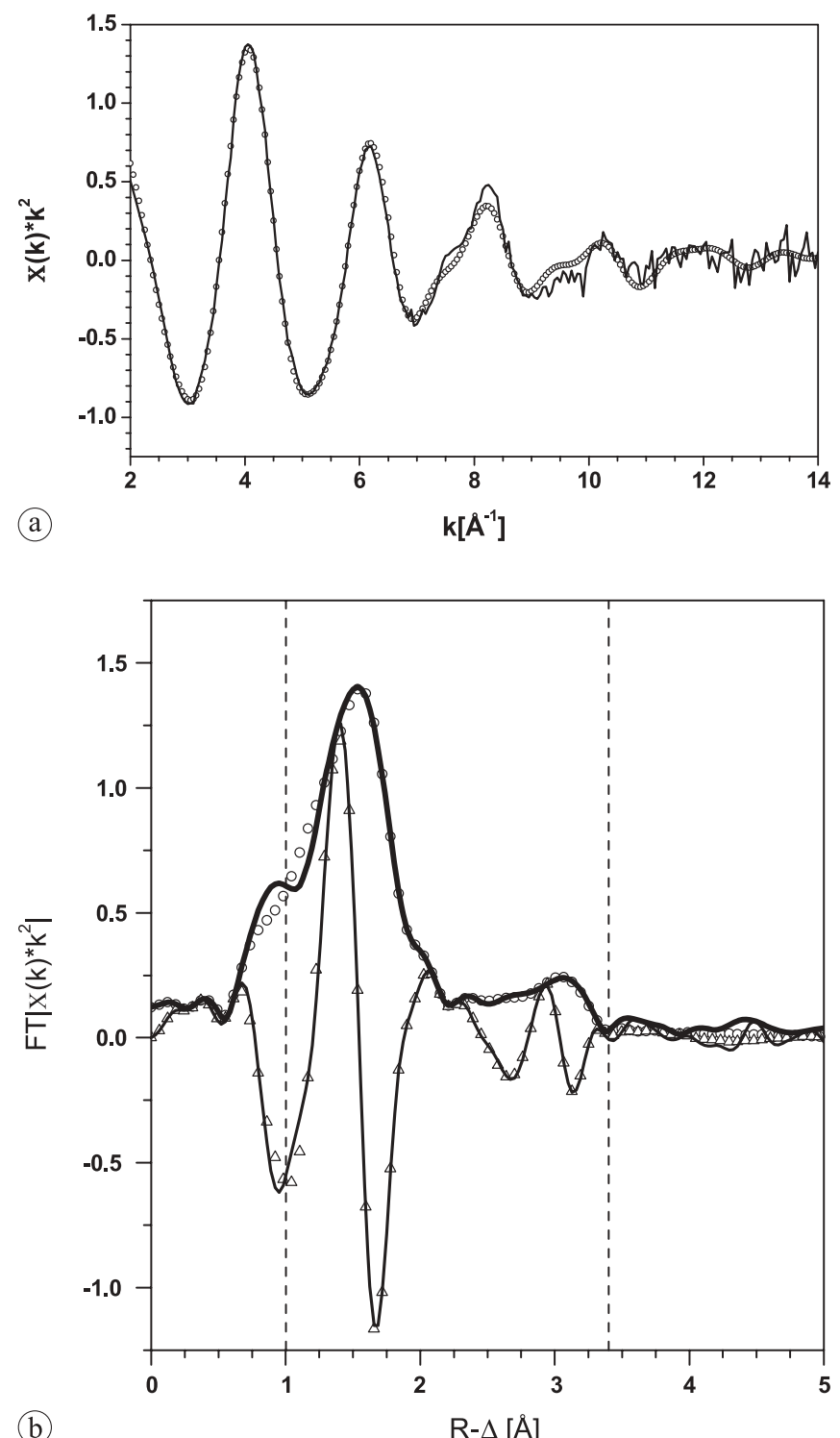

Fig. 3. (a) $k^{2}$-weighted $\mathrm{Zr} L_{3}$ EXAFS of the sample (solid line) and fit result (open circles); (b) FT magnitude (thick solid line), imaginary part (thin solid line), and fit result (open triangles and circles). FT is performed in the range $2.3-13.9 \AA^{-1}$. FT fit range borders are indicated with dashed lines.

$\mathrm{Zr}$ is located out of the $\mathrm{Al} / \mathrm{Mg}$ layer, bonding then with two $\mathrm{Al} / \mathrm{Mg}$. The $\mathrm{Cl}$ atom will then come in the vicinity of $\mathrm{Zr}$ and could explain that one $\mathrm{Cl}$ integrates the first coordination shell. These results are also compatible with a bidentate sorption species but this possibility of a sorption species is ruled out by the results of the treatment of the $\mathrm{Mg}-\mathrm{Al}-\mathrm{Zr}-\mathrm{Cl}$ $\mathrm{LDH}$ with an ammonium carbonate solution as reported in 
this paper. Therefore, we argue as for the Eu case that the $\mathrm{Zr}$ atom is likely incorporated into the $\mathrm{LDH}$ structure but as a defect.

\section{Conclusions}

Within a couple of months a non-irradiated metallic $\mathrm{UAl}_{x^{-}}$ $\mathrm{Al}$ fuel element sample corroded completely in the presence of Fe-II ions in a final repository salt brine solution at $90^{\circ} \mathrm{C}$. In the corrosion products a crystalline phase component was identified as $\mathrm{Mg}-\mathrm{Al}-\mathrm{Cl} \mathrm{LDH}$. The ability of this component to retard radionuclide species by incorporation was investigated. As element species the tetravalent zirconium was chosen.

A synthesis of a Mg-Al-Zr LDH with chloride as interlayer anion was performed. From the analytical data the formula of the $\mathrm{Mg}-\mathrm{Al}-\mathrm{Zr}-\mathrm{Cl} \mathrm{LDH}$ can be derived as $\left[\mathrm{Mg}_{3} \mathrm{Al}_{0.93} \mathrm{Zr}_{0.099}(\mathrm{OH})_{8}\right] \mathrm{Cl}_{0.94}\left(\mathrm{CO}_{3}{ }^{2-}\right)_{0.03} \cdot 2.71 \mathrm{H}_{2} \mathrm{O}$. Proofs for the successful incorporation of the tetravalent $\mathrm{Zr}$ can be given as follow:

- The molar ratio of Mg-Al-Zr did not change, when this LDH was treated with an ammonium carbonate solution. No $\mathrm{Zr}$ was detected in solution and the remaining solid, analyzed by XRD, showed only the typical LDH reflexes.

- SEM-EDX investigations clearly showed the typical sand rose structure and a homogeneous element distribution. No by products were detected.

- The Rietveld refinement of the XRD measurement showed that the synthesized material consists of a LDH with a high degree of stacking disordering. No additional phases could be detected directly.

- Investigations performed by EXAFS spectrometry did show clearly, that in the first coordination shell of the $\mathrm{Zr}$ atom $5 \mathrm{OH}$ groups and one chloride atom is present, hence $\mathrm{Zr}$ possess an octahedral No $\mathrm{Zr}-\mathrm{Zr}$ interaction can be evidenced, excluding the formation of cluster or polynuclear species such in $\mathrm{Zr}$ oxide or hydroxide within the EXAFS detection limit.

Nevertheless, the exact position of the $\mathrm{Zr}$ in the crystal lattice structure of the LDH is not clear yet. Because of the high degree of stacking disordering of the $\mathrm{LDH}$, especially improvements of the structural models are necessary. This work is in progress.

Acknowledgment. This work was financially supported by the Bundesministerium für Forschung und Technologie (BMBF, Förderkennzeichen: 02 E 10357). We acknowledge the ANKA (Angströmquelle Karlsruhe) for providing the beam and infrastructure.

\section{References}

1. Thamm, G.: Disposal of irradiated fuel elements from German research reactors - Status and Outlook, Trans. Int. Conf. Research Reactor Fuel Management (RRFM 1999), Bruges, Belgium (1999), p. 159.

2. Brücher, H., Curtius, H., Fachinger, J., Kaiser, G., Mazeina, L., Nau, K.: Untersuchungen zur Radionuklidfreisetzung und zum
Korrosionsverhalten von bestrahltem Kernbrennstoff aus Forschungsreaktoren unter Endlagerbedingungen. Report Forschungszentrum Jülich, Jül-4104, ISSN 0944-2952 (2002).

3. Mazeina, L., Curtius, H., Fachinger, J., Odoj, R.: Characterisation of secondary products of uranium-aluminium material test reactor fuel element corrosion in repository-relevant brine. J. Nucl. Mater. 323, 1 (2003).

4. Miyata, S.: The synthesis of hydrotalcite-like compounds and their structures and physico-chemical properties. Clays Clay Miner. 31, 369 (1975).

5. (a) Stumpf, T., Curtius, H., Walther, C., Dardenne, K., Ufer, K., Fanghänel, T.: Incorporation of Eu(III) into hydrotalcite: a TRLFS and EXAFS study. Environ. Sci. Technol. 41(9), 3186 (2007); (b) Curtius, H., Ufer, K.: Eu incorporation behaviour of a Mg-Al-Cl layered double hydroxide. Clays Clay Miner. 55(4), 354 (2007).

6. Ufer, K., Kleeberg, R., Bergmann, J., Curtius, H., Dohrmann, R.: Refining realstructure parameters of disordered layer structures within the Rietveld method. Z. Kristallogr. Suppl. 27, 151 (2008).

7. Das, N. N., Konar, J., Mohanta, M. K., Srivastava, S. C.: Adsproption of $\mathrm{Cr}(\mathrm{VI})$ and $\mathrm{Se}(\mathrm{IV})$ from their aqueous solutions onto $\mathrm{Zr}^{4+}$-substituted $\mathrm{ZnAl} / \mathrm{MgAl}$-layered double hydroxides: effect of $\mathrm{Zr}^{4+}$ substitution in the layer. J. Colloid Interface Sci. 270, 1 (2004).

8. Velu, S., Ramaswamy, V., Ramani, A., Handa, B. M., Sivasanker, S.: New hydrotalcite-like anionic clays containing $\mathrm{Zr}^{4+}$ in the layers. Chem. Commun. 2107 (1997).

9. Intissar, M., Jumas, J.-C., Besse, J.-P., Leroux, F.: Reinvestigation of the layered double hydroxide containing tetravalent cations: $\underline{\text { Unambiguous }}$ response provided by X $\underline{X} \underline{A} \underline{S}$ and Mö̈ssbauer spectroscopy. Chem. Mater. 15, 4625 (2003).

10. Rietfeld, H. M.: Line profiles of neutron-powder-diffraction peaks for structure refinement. Acta Cryst. 22, 151 (1967).

11. Hill, R. J., Fischer, R. X.: Profile agreement indices in Rietfeld and pattern-fitting analysis. J. Appl. Cryst. 23, 462 (1990).

12. Bergmann, J., Friedel, P., Kleeberg, R.: BGMN - a new fundamental parameter based Rietveld program for laboratory X-ray sources, it's use in quantitative analysis and structure investigations. Commission of Powder Diffraction, International Union of Crystallography, CPD Newsletter Vol. 20, p. 5 (1998).

13. Treacy, M. M. J., Newsam, J. M., Deem, M. W.: A general recursion method for calculating diffracted intensities from crystals containing planar faults. Proc. R. Soc. Lond. Ser. A 433, 499 (1991).

14. Ennadi, A., Legrouri, A., De Roy, A., Besse, J. P.: X-ray diffraction pattern simulation for thermally treated $[\mathrm{Zn}-\mathrm{Al}-\mathrm{Cl}]$ layered double hydroxide. J. Solid State Chem. 152, 568 (2000).

15. Cheary, R. W., Coelho, A. A.: A fundamental parameters approach to X-ray line-profile fitting. J. Appl. Cryst. 25, 109 (1992).

16. Newville, M.: IFEFFIT interactive XAFS analysis and FEFF fitting. J. Synchrotron Radiat. 8, 322 (2001).

17. Ravel, B., Newville, M.: ATHENA, ARTEMIS, HEPHAESTUS: data analysis for X-ray absorption spectroscopy using IFEFFIT. J. Synchrotron Radiat. 12, 537 (2005).

18. Bellotto, M., Rebours, B., Clause, O., Lynch, J., Bazin, D., Elkaim, E.: A reexamination of hydrotalcite crystal chemistry. J. Phys. Chem. 100, 8527 (1996).

19. Weiss, A., Toth, E.: Untersuchungen zur Synthese, Quellungseigenschaften und Anionenaustausch von kristallchemisch modifizierten Doppelhydroxiden vom Hydrotalkit-Typ. Jahrestagung der DTTG, Freiberg (1996), p. 267.

20. Roelofs, J. C. A. A., van Bokhoven, J. A., Van Dillen, A. J., Geus, J. W., de Jong, K. P.: The thermal decomposition of Mg-Al Hydrotalcites: Effects of interlayer anions and characteristics of the final structure. Chem. Eur. J. 8, 5571 (2002).

21. Mistra, C., Perrota, J.: Composition and properties of synthetic hydrotalcites. Clays Clay Miner. 40, 145 (1992).

22. Duff, C. M., Coughlin, J. U., Hunter, D. G.: Uranium co-precipitation with iron oxide minerals. Geochim. Cosmochim. Acta 66, 3533 (2002). 